\title{
Cellular and molecular mechanisms of the demyelination in the central nervous system and cell therapy approaches
}

\author{
Tsymbaliuk V. I., Semenova V. M., Pichkur L. D., Velychko O. N., Egorova D. M. \\ A. P. Romodanov State Institute of Neurosurgery NAMS of Ukraine, Kyiv, Ukraine \\ e-mail: seveme22@rambler.ru
}

\section{ABSTRACT}

The review summarizes the current concepts of cell-tissue and molecular features of development of demyelinating processes in the central nervous system related to multiple sclerosis and its animal model - experimental allergic encephalomyelitis. An analysis of recently published studies of this pathology, carried out with light and electron microscopy and immunohistochemical and molecular genetic methods, is given. New methodological approaches to the study of the pathomorhological aspects of demyelinating disorders allowed receiving in-depth understanding of the etiology and mechanisms of demyelination processes in the brain and spinal cord tissues at the cellular level and identifying the ways to develop effective modern methods of pathogenetic treatment of these diseases using cell therapy.

KEYWORDS: demyelinating diseases of the central nervous system; experimental allergic encephalomyelitis; neural precursor cells; cell therapy

Despite more than a century of studying the pathogenesis of demyelinating diseases of the central nervous system (CNS), their treatment is one of the unsolved problems of modern medicine. Among them, multiple sclerosis (MS) is characterized by the most complex pathology and is a multifactorial, autoimmune progressive neurodegenerative process with a remittent course and a variety of clinical manifestations. In terms of severity among neurological diseases, MS ranks fourth after strokes, Parkinson's disease and epilepsy, and one of the first places among causes of young patients disability [1].

At MS, there is a multifocal lesion of the myelin sheath of axons in the brain and spinal cord white matter with subsequent violation of the conduction of nerve impulses. Although the etiology of MS remains unclear, the development of autoimmune reactions against its own antigens of the nervous tissue is considered the main factor in the initiation of the demyelinating process, which is accompanied by a specific inflammatory reaction with the initiation of the process of demyelination of nerve fibers [1, 2]. The process of demyelination at MS is a consequence of inflammatory lesions, predominates in white matter and causes the development of neurological deficiencies [3].

Recently, due to the use of new methodological approaches in the study of pathomorphology and immunology of demyelinating diseases, new data have appeared that contribute to an in-depth interpritation of the pathogenesis of this pathology. This review analyzes the scientific literature of recent years concerning cellular and tissue mechanisms of the development of demyelinating diseases in the central nervous system and MS, in particular.
Thus, an essential factor in the initiation and progression of demyelination of nerve fibers is the irreversible damage of oligodendroglia cells. The loss of myelin and the death of myelinizing oligodendrocytes cause a conductive disorder of axons function and appearance of neurological symptoms $[4,5]$. It is also proved that the leading role in the development of demyelination process of nerves belongs to T-helpers [6] and macrophages - main effector cells, acting against neural cells [7]. Moreover, it was shown that in addition to migrated from blood monocytes, which infiltrate the nerve tissue, resident perivascular and meningeal macrophages, as well as microglial cells, take part in the destruction of myelin [7, 8]. On the other hand, local macrophages involved in limiting of the autoimmune reaction can contribute to the repair of damaged CNS tissue $[7,8]$.

Macrophage infiltration of damaged CNS tissue and activation of microglial cells detected in MS are also observed in the autoimmune experimental allergic encephalomyelitis (EAE) model in animals, which is an adequate experimental multiple sclerosis model [9]. This model showed that the development of neurodegenerative changes in neural tissue cells is an essential mechanism in the initiation and regulation of the local inflammatory response in EAE [10].

At present, in the interpritation of mechanisms of the MS development, much attention is paid to microglia cells, since they play a key role in the process of inflammatory neurodegeneration in the acute and chronic stage of MS. These highly specialized cells include neurotoxic pathways, produce pro-inflammatory cytokines, free radicals of oxygen 
and nitrogen, and secrete proteolytic enzymes, causing progressive neurodegeneration. Microglia cells participate in the development of cortical lesions in MS, as well as in damage of synaptic transmission in autoimmune encephalomyelitis [11].

In recent years, cell-tissue mechanisms of the development of demyelinating diseases have been studied using new methodological approaches, which revealed new patterns in the dynamics of the course of this pathology. Thus, Trifunović D. et al. investigated the processes of apoptosis and necrosis in EAE in the ED1+ cell population (macrophages / activated microglia) of the spinal cord in rats by the TUNEL method, as well as by immunohistochemical staining for cleaved caspase 3 [10] They found that at the peak of EAE development infiltrates of immune cells contain ED1 $1^{+}$, TUNEL ${ }^{+}$and caspase $3^{+}$positive cells in both white and gray matter of the spinal cord. However, compared to the gray matter, there were found more dead ED1 ${ }^{+}$cells in white matter both in the general population and in the infiltrated parts of the spinal cord. On this basis, the authors suggested that the activated macrophages / microglia in the gray matter of the spinal cord, in comparison with the white matter, are less susceptible to the induction of cell death. This may indicate that internal mechanisms and characteristics of EAE appear to differ in the white and gray matter of the spinal cord, since macrophages and microglial cells of gray matter are less susceptible to induced death [10].

Another mechanism in the development of MS is the penetration of autoreactive T-cells sensitized by the myelin basic protein (MBP) into the nerve tissue, followed by the initiation of an inflammatory process leading to apoptosis of neural cells and demyelination with axonal destruction. It is suggested that the reason for this phenomenon is the escape from apoptosis of autoreactive cells to the MBP during clonal selection in the thymus [12].

According with data of Gilerovich et al in the spinal cord of Wistar rats during acute EAE induced by injection of homological spinal cord homogenate occur the reactive changes of neurons, astrocytes, ependymocytes. In addition, the heterogeneous inflammatory processes such as cells infiltration both in gray and white matter of spinal cord as well as in the area of the cauda equina roots are observed [13]. Cellular infiltrates, consisting of leukocytes, lymphocytes and microglial cells, were also detected perivascular with the formation of sleeve-like structures.

Authors' use of the immunohistochemical method to detect the proliferating cell nuclear antigen (PCNA) in spinal cord tissue in animals with model of EAE showed a different degree of proliferative activity depending on the intensity of the inflammatory autoimmune process, regardless of the level of lumbar spinal cord thickening. The presence of inflammatory infiltrates was also accompanied by microstructural dystrophic changes in motoneurons of the ventral horns of the spinal cord in the form of hyperchromatosis of the nuclei, deformation and vacuolization of the cytoplasm. Along with this, such motoneurons showed signs of an axonal reaction induced by damage to the conducting pathways of the spinal cord. Sensitive neurons of the dorsal horns of the spinal cord were also particularly damaged. This was accompanied by hyperplasia of astrocytes with the formation of astrogliosis sites and reactive changes in the ependymocytes of the central canal of the spinal cord with the formation of multiserial structures [13].

Of great practical importance is the heterogeneity of the histological manifestations of the EAE at the peak of the disease in rats depending on the severity of the clinical picture, as well as involvement of the spinal cord, vessels, neural cells or pathways in the pathological process. This is confirmed by the results of both traditional light-optical and immunohistochemical studies of proliferating cell nuclear antigen (PCNA), marker of astrocytes glial-fibrillary acidic protein (GFAP), and a marker of microglial cells and macrophages (lba-1). According to the degree of expression of these signs, the authors identified 4 typical variants of morphological manifestations of the EAE [14]. Thus, it was possible to confirm that the main characteristic of MS pathogenesis is the destruction of neural cells and myelin sheaths of the central nervous system, as well as immune cells that infiltrate the nerve tissue. The death of pro-inflammatory cells is extremely important for limiting the autoimmune response in the dynamics of the development of MS [15].

When studying the role of cell degeneration in the development of the inflammatory process in the central nervous system in the MS, regional specificity regarding the susceptibility of immune cells to cellular decay products is also actively studied. The constantly increasing volume of scientific evidence points to the importance of inflammation and atrophy of the gray matter of the spinal cord in the pathogenesis of the demyelinating process, in particular, in MS. The pathology of the gray matter of the spinal cord largely determines the physical disability of patients with relapses of MS and its secondary progression [16]. Thus, in the clinical variant of the progressive course of MS, the atrophy of the gray matter of the spinal cord is more pronounced in comparison with the relapsing forms of the disease $[10,17]$. This is confirmed by the observation of the detected gray matter damage in postmortem samples of the spinal cord of MS patients, revealed by magnetic resonance imaging [18].

Autoimmune encephalomyelitis was originally referred to a «white matter disease». Later, it was found that in MS pathological changes are also determined in the gray matter in the form of loss and/or atrophy of motor neurons in the brain tissue $[19,20]$. Fahmy $H$. et al. found perivascular clusters of mononuclear cells, proliferation of gliocytes, as well as signs of degeneration and death of a part of neurons in the cortical area in the pathohistological study of brain tissue of the rats with induced EAE [21]. That was combined with the formation of sites of diffuse gliosis in the white matter of the brain and with perivascular clusters of mononuclear cells.

Al-Iziki et al. revealed signs of destruction of motoneurons, perivascular clusters of mononuclear cells in deep gray matter, as well as proliferation of gliocytes with the presence of diffuse gliosis foci in white substance in deep gray matter while studying morpho-functional manifestations of EAE up to 28 days after immunization of experimental animals by pathohistological examination of the brain [22].

Fahmy $\mathrm{H}$. et al. observed different degrees of demyelination of the nerve fibers in the cerebral cortex and hippocampus, from partial to full, using the electron microscopy in the study of the brain of rats with EAE [21].

Bando $Y$. et al. using the scanning electron microscopy deepened the notion of the pathology of nerve fibers demyelination in EAE in mice [23]. Ultrastructural anomalies of myelin structures and axonal organoids in the white matter of the spinal cord are shown in the form of detachment and excessive accumulation of myelin, formation of axoplasmic reticular structures, and the accumulation of mitochondria of the atypical structure in degenerating and degenerated axons. Immunohistochemistry in EAE also revealed the dysfunction of the mitochondrial fission and fusion process in the axons of the spinal cord in EAE.

More than a half of MS patients suffer from cognitive disorders, including learning and memory dysfunction. However, the mechanisms for the development of these clinical deficits have not been studied properly. In this regard, Ziehn M. et al. on models of neurodegenerative disease, including EAE, morphologically evaluated the extent of manifestations of hippocampal neurodegeneration and an inflammatory reaction in the brain tissue [24]. There is a neuronal damage with the loss of synapses in the hippocampus of such animals, which correlated with deterioration in their cognitive ability. The pathological changes in neurons in the hippocampus begin already in the early stages of EAE development and are attended by a decrease in the content of neurons in the pyramidal layer CA1, as well as the loss of inhibitory interneurons and glial cells. According to the observations of Ziehn M. et al., these effects develop against the background of chronic activation of microglial cells and the accumulation of immune cells migrating from the blood, which is accompanied by diffuse demyelination of the neuronal axons of the hippocampus without a noticeable decrease in their density [24]. In this case, the presynaptic release apparatus is reduced and the synaptic protein is expressed in the hippocampal neurons. These morphostructural changes can also cause a decreasing of the function of hippocampal-dependent spatial learning. 
These results demonstrate that the development of an autoimmune demyelinating disease in the hippocampus also causes neurodegenerative changes. It is suggested to use this model for preclinical evaluation of the effectiveness of various treatment methods aimed at preventing hippocampal neuropathology and dysfunction in MS [24].

In recent years, in the treatment of patients with demyelinating diseases and MS, immunomodulating therapy with the application of fetal neural cells has been used. However, the effect of fetal neural cells on apoptotic processes in the central nervous system and thymus in MS and its model of EAE has not been studied sufficiently [12].

Another modern methodological approach to the treatment of $E A E$ is the method of activating the genes involved in the induction of cell death - apoptosis. The p53 protein has this ability due to its transcriptional function and direct participation in the induction of the mitochondrial pathway of apoptosis [25]. It was shown that DNA damage promotes the accumulation of p53, which, in its turn, blocks the course of the cell cycle in G1 phase, preventing DNA replication and repair of damage [26]. If the repair is not possible, the p53 protein triggers the apoptosis [25].

According to observations of Goltsev A. et al. in the pre-manifestation period of the development of EAE ( $7^{\text {th }}$ day), there was no significant decrease in the absolute number of $p 53^{+}$cells in the thymus [12]. At the same time, a gradual decrease in the content of such cells during the 7-28 days of EAE development may indicate a violation of their negative selection by apoptosis of tissue-specific autoreactive T-cells. Thus, on the $28^{\text {th }}$ day of EAE development in rats, the content of $p 53^{+}$cells had 2-fold decrease compared with the control. However, on the $35^{\text {th }}$ day of $E A E$, with an decrease in the clinical signs of pathology, a 3-fold increase was observed [12]. The transplantation of fetal neural cells provided decrease in the absolute number of $\mathrm{p} 53^{+}$cells in the thymus of rats on the $21^{\text {st }}$ day of EAE.

Analysis of the intensity of apoptotic processes in the inflamed area of brain with EAE showed that, starting from the $7^{\text {th }}$ day of the pathological process development, an increase in the content of $p 53^{+}$cells was noted. On the $21^{\text {st }}$ day, clinical signs of the disease were accompanied by the accumulation of a maximum number of cells in the state of apoptosis with a further decrease in the intensity of apoptotic processes to the values characteristic of an intact organism. The transplantation of native and cryopreserved fetal neural cells significantly reduced the content of ${\mathrm{p} 53^{+}}^{+}$cells in animals with EAE during the whole observation period (2135 days). Thus, the transplanted fetal neural cells enhance apoptosis of autoreactive T-cells by activating costimulatory molecules on antigen presenting cells, thereby reducing apoptosis in the brain [12]

The results show that the involvement of new methodological approaches to the study of the pathomorphological aspect of demyelinating diseases in the central nervous system contributes to a new in-depth understanding of the etiology and mechanisms of this disease progression at the cellular, subcellular and molecular levels. That stimulated the development of new modern methods of pathogenetic treatment of these diseases using cell therapy.

At present, regional interactions of neural precursor cells (NPCs) and brain tissues of the recipient are being studied in chronic-remitting inflammatory processes. Theotokis $P$. et al. note that exogenous transplanted NPCs exhibit various immunomodulatory effects, as shown in experimental models of autoimmune demyelination [27]. The authors used a MOG-induced model (myelin oligodendrocyte glycoprotein 3555 peptide) of experimental chronical autoimmune encephalomyelitis in $\mathrm{C} 57 \mathrm{BL} / 6$ mice on the $50^{\text {th }}$ day after induction of the demyelination. They studied the expression of connexin 43 (Cx43) and connexin 47 (Cx47) after intraventricular transplantation of GFP+ NPCs during their integration with the host tissue. $\mathrm{C} \times 43$ and $\mathrm{C} \times 47$ are the two key proteins of glial gap junctions (GJs). It was found that on the $50^{\text {th }}$ day NPCs migrated to the brain parenchyma and were detected in corpus callosum at the level of the lateral ventricles and hippocampus. Most $\mathrm{GFP}^{+}$cells were differentiated with formation of single or branching processes, and mainly expressed the markers of mature glia (GFAP and Nogo-A). This was accompanied by a significant reduction in the number of glial cell precursors. GFP+ NPCs also expressed connexins and formed GJs around the hippocampus largely than near the lateral ventricles. The presence of NPCs did not increase the Cx43 GJS in EAE, but prevented the reduction of oligodendrocyte $\mathrm{C} \times 47$, increased the number of oligodendrocytes, and local levels of $\mathrm{C} \times 47$ and Cx47 GJs per cell. These results justify that transplanted NPCs can have numerous positive effects in demyelinating processes in brain tissue, including their direct integration into glial syncytium and differentiation. In addition, they can also prevent GJs losses in oligodendrocytes and increase in the recruitment of myelinating glial cells to the areas of demyelination [27].

Recently, methods of cell therapy with the application of mesenchymal stem cells (MSCs) obtained from various sources have also been tested in the experiment for the treatment of demyelinating diseases in the CNS. A number of experimental studies showed the ability of adipose-derived MSCs to migrate towards demyelinated areas of the brain in experimental autoimmune encephalomyelitis. Transplantation of MSCs in mice with EAE promotes the recovery of the number of endogenous oligodendrocytes, which remyelinated the damaged nerve fibers [28]. Later on the EAE model in rats it was established that MSCs transplantation could also lead to suppression of autoreactive clones of lymphocytes and repair of the myelin sheath of damaged axons with restoration of neurologic functions [29,30]. It is also believed that multipotent MSCs contribute to the activation of endogenous mechanisms of repair due to the secretion of soluble trophic factors. It is interesting to note that the main effects observed during MSCs transplantation can be replicated with the injection of a conditioned medium from these cells [31].

Nowadays, it is also established that autologous transplantation of MSCs in patients with multiple sclerosis allows to achieve stabilization of neurological status and to reduce the risk of active foci of demyelination. In addition, the use of MSCs in demyelinating diseases makes it possible to provide an immunomodulating effect without the use of immunosuppressive therapy [32].

Despite the fact that the etiopathogenesis of autoimmune diseases is not studied yet, the decisive role of many cytokines in the pathogenesis of encephalomyelitis and multiple sclerosis is now determined [33]. Thus, such cytokines as a tumor necrosis factor, interleukin-6 (IL-6) stimulate the production of proinflammatory mediators involved in nerve tissue damage $[34,35]$. In contrast to IL-6, interleukin-10 (IL-10) with a mass of about $35 \mathrm{kDa}$, produced by T-helper type 2, activates monocytes/ macrophages and regulatory T-cells. In addition, IL-10 inhibits the production of T-helper type 1 and pro-inflammatory cytokines, including interferon gamma (IFN- $\gamma$ ), interleukins 2 and 12 (IL-2, IL-12) and tumor necrosis factor alpha (TNF-a) [36]. This served as a rationale for the clinical application of IL-10 in autoimmune diseases [37, 38].

In modern studies many laboratories use transduction of bone marrow-derived MSCs by IL-10 using the retroviral vector MIG (MSCVIRES-GFP) and the MIG-IL10 vector [37, 39]. However, the expected results of the transfected MSCs in this way may be unpredictable due to the insufficiently studied possible ways of migration of these cells in the body and the properties of the virus itself. Therefore, the effect of transfected MSCs without using the viral vector is often studied in the EAE model $[40,41,42,43]$.

In the complex research Tsymbaliuk $\mathrm{V}$. et al. studied the effect of MSCs, interleukin-10 (IL-10), a combination of MSCs+IL-10 and MSCs transfected with a plasmid vector containing the IL-10 gene (MSCT) in the rat's EAE model on the function of the central nervous system [44, 40]. Testing in the open field established that, on the $12^{\text {th }}$ day of the experiment, animals with EAE showed decline the exploratory behavior and increase of emotional activity in animals. A comparative study of the effect of different treatment options with the application of MSCs, IL-10, MSCs+IL-10, MSCT on the behavior of rats with induced EAE in the open field test revealed that the combined use of MSCS+IL-10 was most effective in correcting behavioral disturbances of experimental animals. 


\section{CONCLUSION}

The presented review testifies that by the present time due to the complex application of classical pathomorphology and modern methods of molecular neurobiology, cytochemistry and cytomorphology, it has been possible to clarify a number of mechanisms in the pathogenesis of the development of MS and a number of demyelinating processes in the central nervous system. Despite this, many aspects of these diverse diseases remain unclear and need further study and search for alternative methods of their treatment using the methods of cell therapy. At the present stage, researchers' efforts are aimed at developing new effective strategies for using the capabilities of stem cells of various origins, reduce the risk for complications and improve the effectiveness of cell therapies. Important factors are also the use of unified methods of examining patients and the evaluation of their treatment results. Compliance with these conditions in the future will allow to evaluate the clinical effectiveness of new methods and to develop indications for the use of innovative approaches for treatment of demyelinating diseases of the CNS using cell therapy.

\section{REFERENCES}

1. Lisyaniy NI. Immunologiya i immunoterapiya rasseyannogo skleroza [Immunology and immunotherapy of multiple sclerosis]. Kiev, 2003. 251 p. [In Russian]

2. Sospedra M, Martin R. Immunology of multiple sclerosis. Annual Review of Immunology. 2005; 23: 683-747.

3. Trapp BD, Bo L, Mo“rk S, Chang A. Pathogenesis of tissue injury in MS lesions. J Neuroimmunol. 1999; 98: 49-56.

4. Herz J, Zipp F, Siffrin V. Neurodegeneration in autoimmune CNS inflammation. Experimental Neurology. 2010; 225: 9-17.

5. Patel J, Balabanov $R$. Molecular mechanisms PC of oligodendrocyte injury in multiple sclerosis and experimental autoimmune encephalomyelitis. International Journal of Molecular Sciences. 2012; 13: 10647-659.

6. Petermann F, Korn T. Cytokines and effector T cell subsets causing autoimmune CNS disease. FEBS Letters. 2011; 585: $3747-757$.

7. Bogie JF, Stinissen P, Hendriks JJ. Macrophage subsets and microglia in multiple sclerosis. Acta Neuropathologica. 2014; 128: $191-213$.

8. Goldmann T, Prinz M. Role of microglia in CNS autoimmunity. Clinical Developmental Immunology. 2013; Avaliable: http://dx.doi.org/10.1155/2013/208093

9. Markov DA. Demieliniziruyushchie zabolevaniya nervnoy sistemy v eksperimente i klinike [Demyelinating diseases of the nervous system in the experiment and in the clinic]. Minsk: Nauka i tekhnika, 1975. 360 p. [In Russian]

10. Trifunović D, Djedović N, Lavrnja I, et al. Cell death of spinal cord ED1+'cells in a rat model of multiple sclerosis. PeerJ. 2015; Avaliable: https://doi.org/10.7717/ peerj. 1189

11. Correale J. The role of macroglial activation in disease progression. Multiple Sclerosis Journal. 2014; 20(10): $1288-295$.

12. Goltsev AA, Porozhan EA, Babenko NN, et al. Apopticheskie protsessy v timuse i golovnom mozge pri razvitii eksperimental'nogo allergicheskogo entsefalomielita do i posle lecheniya fetal'nymi nervnymi kletkami [Apoptotic processes in thymus and brain during experimental allergic encephalomyelitis development before and after treatment with fetal neural cells]. Patologiya - Pathology. 2011; 8(2): 69-72. [In Russian]

13. Gilerovich EG, Fedorova EF, Karpenko MN, et al. Reaktivnye izmeneniya v strukturakh poyasnichnogo utolshcheniya spinnogo mozga krys pri eksperimental'nom allergicheskom entsefalomielite [Reactive changes in the structures of lumbar spinal cord thickening in rats with experimental allergic encephalomyelitis]. Proceedings of the VIII All-Russian Conference on Cell Pathology 11-12 November 2010. M.: MDV, 2010. p. 324. [In Russian]

14. Gilerovich EG, Fedorova EA, Abdurasulova IN, et al. Analiz morfologicheskikh proyavleniy vospalitel'noy reaktsii v spinnom mozgu krys Vistar na eksperimental'noy modeli [Analysis of morphological manifestations of the inflammatory reaction in wistar rat spinal cord in experimental model]. Morfologiya - Morphology. 2010; 138(5): 16-20. [In Russian]

15. Pender MP, Rist MJ. Apoptosis of inflammatory cells in immune control of the nervous system: role of glia. Glia. 2001; 36(2): 137-44.

16. Kearney H, Schneider T, Yiannakas MC, et al. Spinal cord gray matter abnormalities are associated with secondary progression and physical disability in multiple sclerosis. Journal of Neurology, Neurosurgery \& Psychiatry. 2014; 86(6): 608-14.

17. Schlaeger R, Papinutto N, Panara V, et al. Spinal cord gray matter atrophy correlates with multiple sclerosis disability. Annals of Neurology. 2014; 76: 568-80.

18. Gilmore $C P$, Geurts JJ, Evangelou N, et al. Spinal cord gray matter lesions in multiple sclerosis detected by post-mortem high field MR imaging. Multiple Sclerosis. 2009; 15: 180-88.

19. Derfuss T, Parikh H, Velhin S, et al. Contactin-2/TAG-1-directed autoimmunity is identified in multiple sclerosis patients and mediates gray matter pathology in animals. Proc Natl Acad Sci USA. 2009; 106(20): 8302-307.

20. Rudick RA, Trapp BD. Gray-matter injury in multiple sclerosis. N Engl J Med. 2009; 361: 1505-550.

21. Fahmy HM, Noor NA, Mohammed FF, et al. Nigella sativa as an anti-inflammatory and promising remyelinating agent in the cortex and hippocampus of experimental autoimmune encephalomyelitis-induced rats. The Journal of Basic \& Applied Zoology. 2014; 67(5): 182-95.

22. Al-Izki S, Pryce G, O'Neill JK, et al. Practical guide to the induction of relapsing progressive experimental autoimmune encephalomyelitis in the Biozzi ABH mouse. Mult Scler Relat Disord. 2012; 1: 29-38.

23. Bando $Y$, Nomura $T$, Bochimoto $H$, et al. Abnormal morphology of myelin and axon pathology in murine models of multiple sclerosis. Neurochemistry International. 2015; 81: 16-27.

24. Ziehn M0, Avedisian AA, Tiwari-Woodruff S, et al. Hippocampal CA1 atrophy and synaptic loss during experimental autoimmune encephalomyelitis. Lab Invest. 2010; 90(5): 774-86.

25. Chumakov PV. Belok r53 i ego universal'nye funktsii v mnogokletochnom organizme [The p53 protein and its universal functions in the multicellular organism]. Uspekhi Biologicheskoi Khimii. - Advances in biochemical chemistry. 2007; 47: 52-53. [In Russian]

26. Braithwaite $A, L u X$. Some p53-binding proteins that can function as arbiters of life and death. Cell death and differentiation. 2006; 13: 984-93.

27. Theotokis $P$, Kleopa KA, Touloumi 0 , et al. Connexin43 and connexin47 alterations after neural precursor cells transplantation in experimental autoimmune encephalomyelitis. Glia. 2015; 63(10): 1772-783.

28. Constantin G, Marcon S, Rossi B, et al. Adipose-derived mesenchymal stem cells ameliorate chronic experimental autoimmune encephalomyelitis. Stem Cells. 2009; 27: $2624-635$

29. Dai L, Lennon DP, Eaton V, et al. Human bone marrow-derived mesenchymal stem cell induce Th2 polarized immune response and promote endogenous repair in animal models of multiple sclerosis. Glia. 2009; 57: 1192-209. 
30. Barhum $Y$, Gai-Castro S, Bahat-Stromza $M$, et al. Intracerebroventricular transplantation of human mesenchymal stem cells induced neurotrophic factors attenuates clinical symptoms in a mouse model of multiple sclerosis. J Mol Neurosci. 2010; 41: 129-37.

31. Bai L, Lennon DP, Caplan Al, et al. Hepatocyte growth factor mediates mesenchymal stem cell-induced recovery in multiple sclerosis models. Nature Neuroscience. 2012; 15: 862-70.

32. Fedulov AS, Borisov AV, Moskovskykh YuV, et al. Autologichnaya transplantatsiya mezenkhimal'nykh stvolovykh kletok kak metod modifikatsii klinicheskogo techeniya rasseyannogo skleroza [Autologous mesenchymal stem cells transplantation as a method of modifying the clinical course of multiple sclerosis]. Nevrologiya i neyrokhirurgiya. Vostochnaya Evropa - Neurology and Neurosurgery. Eastern Europe. 2016; 4: 516-522. [In Russian]

33. Zheleznikova GF, Skripnenko NV, Ivanova GP, et al. Faktory immunopatogeneza rasseyannogo skleroza [Factors of immunopathogenesis of multiple sclerosis]. Ros immunolog zhurn. - Russian Journal of Immunology. 2015; 9(3): 261-82. [In Russian]

34. Zafranskaya MM, Nizheharodava DB, Ivanchyk HI, et al. Dinamika tsitokinov u patsientov s rasseyannym sklerozom do i posle kletochnoy terapii [Before and after cell therapy cytokines dynamics balance in multiple sclerosis patients]. Immunopatologiya, allergologiya, infektologiya - Immunopathology, allergology, infectology. 2014; 3: 82-91. [In Russian]

35. Le Blanc K, Le Blanc K, Rasmusson I, Sundberg B. Treatment of severe acute graft-versus-host disease with third party haploidentical mesenchymal stem cells. Lancet. 2004; 363: 1439-441.

36. Klose J, Schmidt N, Melms A, et al. Suppression - of experimental autoimmune encephalomyelitis by interleukin-10 transduced neural stem/progenitor cells. Journal of Neuroinflammation. 2013; 10: 117

37. Min CK, Kim BG, Park G, et al. IL-10-transduced bone marrow mesenchymal stem cells can attenuate the severity of acute graft-versus-host disease after experimental allogeneic stem cell transplantation. Bone Marrow Transplantation. 2007; 39: 637-645.

38. Finnegan A, Kaplan CD, Cao Y, et al. Collagen-induced arthritis is exacerbated in IL-10-deficient mice. Arthritis Res Ther. 2003; 5: 18-24.

39. Kim WU, Lee WK, Ryoo JW. Suppression of collagen-induced arthritis by single administration of poly (lactic-co-glycolic acid) nanoparticles entrapping type II collagen: a novel treatment strategy for induction of oral tolerance. Arthritis Rheum. 2002; 46: 1109-120.

40. Tsymbaliuk VI, Velychko OM, Pichkur OL, et al. Effects of Warton's jelly humans mesenchymal stem cells transfected with plasmid containing il-10 gene to the behavioral response in rats with experimental allergic encephalomyelitis. Cell and Organ Transplantology. 2015; 3(2):139-143. doi: 10.22494/COT.V3I2.14.

41. Kovalchuk MV, Deryabina OG, Pichkur $L D$, et al. Distribution of transplanted human mesenchymal stem cells from Wharton's Jelly in the central nervous systems of the EAE rats. Biopolymers and Cell. 2015; 31(5): 371-78.

42. Peron JP, Jazedje T, Brandão WN, et al. Human endometrial-derived mesenchymal stem cells suppress inflammation in the central nervous system of EAE mice. Stem Cell Rev. 2012; 8(3): 940-52.

43. Rafei M, Birman E, Forner K, Galipeau J. Allogeneic Mesenchymal Stem Cells for Treatment of Experimental Autoimmune Encephalomyelitis. Molecular Therapy. 2009; 17(10): 1799-803.

44. Tsymbaliuk VI, Velychko OM, Pichkur OL, et al. Effects of human Wharton's jelly-derived mesenchymal stem cells and interleukin-10 on behavioural responses of rats with experimental allergic encephalomyelitis. Cell and Organ Transplantology. 2015; 3(1):46-51. doi: 10.22494/COT.V3l1.19

\begin{tabular}{l}
$\mid$ ARTICL ON THE SITE \\
\hline
\end{tabular}

The authors indicate no potential conflicts of interest.

Received: February 21, 2017

Accepted: April 28, 2017 